\title{
Design and Fabrication of Rectifying Antenna Circuit for Wireless Power Transmission System Operating at ISM Band
}

\author{
Doan Huu Chuc ${ }^{1}$, Bach Gia Duong ${ }^{2}$ \\ ${ }^{1}$ Department of Electrical and Electronics, Hai Phong Private University, Vietnam \\ ${ }^{2}$ Department of Electronics and Telecommunications, VNU University of Engineering and Technology, Vietnam
}

\begin{tabular}{|c|c|}
\hline Article Info & ABSTRACT \\
\hline Article history: & This paper introduces an overview of a rectifying antenna (rectenna) circuit \\
\hline Received Mar 30, 2016 & based on a microstrip patch antenna and a microwave double voltage rectifier \\
\hline Revised May 23, 2016 & at $2.45 \mathrm{GHz}$ were designed and fabricated. The antenna's return loss is \\
\hline Accepted Jun 10, 2016 & achieved of $-15 \mathrm{~dB}$ at $2.45 \mathrm{GHz}$. The microwave to DC conversion efficiency \\
\hline Keyword: & $\begin{array}{l}\text { load. The design and simulated results were carried out by the microwave } \\
\text { engineering professional design software, known as ADS2009 package. All }\end{array}$ \\
\hline Antenna & \\
\hline Conversion Efficiency & \\
\hline HSMS2820 & \\
\hline Microwave Power & \\
\hline Transmission & \\
\hline Rectifier & \\
\hline Wireless Power Transmission & All rights reserved. \\
\hline \multicolumn{2}{|l|}{ Corresponding Author: } \\
\hline \multicolumn{2}{|l|}{ Doan Huu Chuc, } \\
\hline \multicolumn{2}{|c|}{ Department of Electrical and Electronics, } \\
\hline \multicolumn{2}{|c|}{ Hai Phong Private University, } \\
\hline \multicolumn{2}{|c|}{36 Dan Lap Road, Le Chan Dist, Hai Phong City, Vietnam. } \\
\hline Email: chucdh@hpu.edu.vn & \\
\hline
\end{tabular}

\section{INTRODUCTION}

Microwave power transmission (MPT) is one of the hot topics in microwave and millimeter wave devices, circuit, and systems. Microwave power transmission has had a long history before the more recent movement toward wireless power transmission (WPT). MPT can be applied not only to beam type point to point WPT but also to an energy harvesting system fed from distributed or broadcasting radio waves. A generic MPT block diagram is shown in Figure 1. A key component in the receiving system is the rectifying antenna, or rectenna. A rectenna, which is used to convert the microwave power to the direct current (DC) power, is one of the key components of the MPT system. A rectenna is a passive element with rectifying diodes that operates without an internal power source. It can receive and rectify microwave power to DC power [1].

Various rectennas can be applied. This depends on requirements for the system and its users. For a rectenna array, the antennas in the rectennas can absorb $100 \%$ of input microwaves. Since the MPT system is an energy system, a rectifying circuit with a higher efficiency is required. Theoretically, various rectennas can achieve $100 \%$ efficiency [1]-[4]. Working frequency plays an important role in design of the rectenna. It is usually determined by the desired application. At low frequencies (below $1 \mathrm{GHz}$ ), high gain antennas tend to be quite large. Increased the frequency allows the use of so many compact antennas. Furthermore, the amount of energy available at a certain distance from a transmitter is given by Friis equation [5]-[7]. 


$$
F_{r}=P_{\mathrm{i}} \cdot G_{\mathrm{i}} \cdot G_{\mathrm{r}} \cdot\left(\frac{\lambda}{4 \pi R^{2}}\right)^{*}
$$

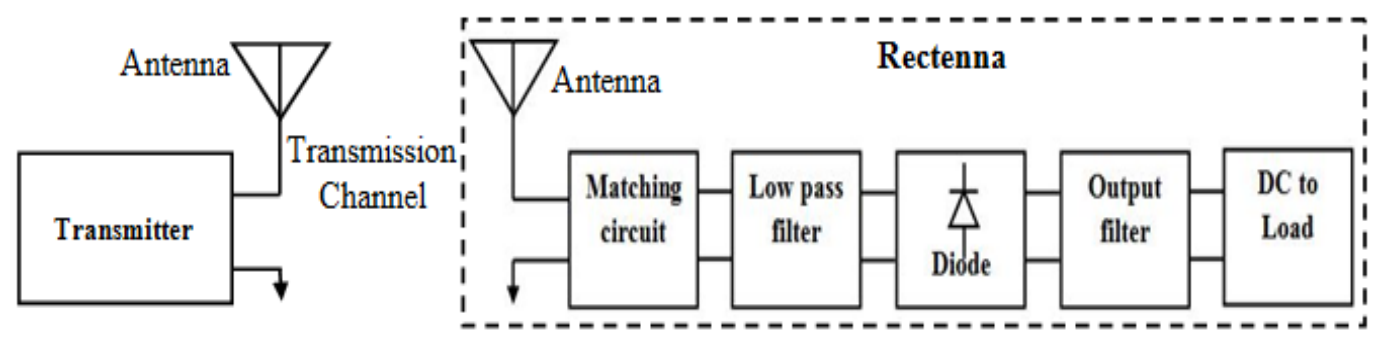

Figure 1. Block diagram of MPT

Where $\mathrm{Pt}$ is the power of the emitter, Gt and $\mathrm{Gr}$ are the emitter and receiver antenna gain respectively, $\lambda$ is the wavelength used and $D$ is the distance separating the emitter and the receiver. The available power at a certain distance from the emitter decreases as the frequency increases. Frequencies in the $1 \mathrm{GHz}-3 \mathrm{GHz}$ range are considered to provide a good compromise between free space attenuation and antenna dimensions.

We have designed, simulated and fabricated a rectifying antenna circuit for microwave power transmission operating at $\mathrm{S}$ band. The first part of this paper presents the patch antenna design problem of a single rectenna circuit. Design and optimization of the derived voltage doubler rectifier model are presented in the subsequent parts. The printed circuit board (PCB) technology is used to minimize the circuit size and losses. Finally, conclusions and extensions of this study are discussed.

\section{ANTENNA DESIGN}

Antenna design is important in the proposed rectenna. The antenna is used to receive transmit electromagnetic energy. In order to reduce the size of the rectenna, the patch antenna was used because of its ease integration with printed circuit board (PCB) technology. A general two-dimensional (2D) representation of a patch antenna is given in Figure 2.

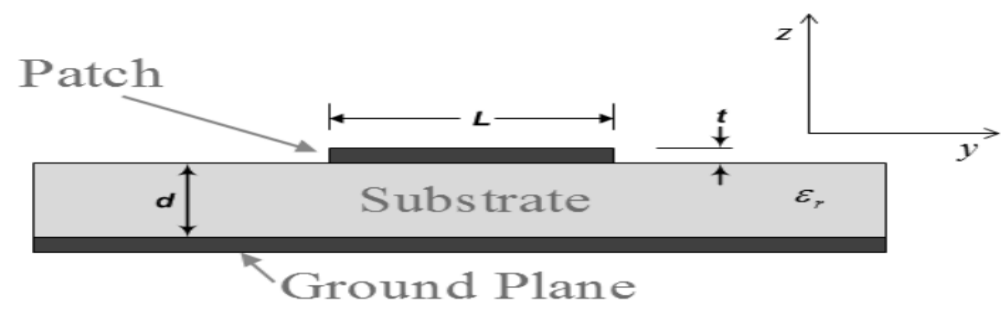

Figure 2. 2D representation of a patch antenna

with $L$ length of the patch, $d$ depth of the substrate, $t$ thickness of the patch.

The characteristics of the antennas are defined mainly by their geometries and the material properties from which they were made. Basically, a microstrip "patch" antenna is a radiator that is placed on top of a grounded dielectric (substrate). The design of patch antennas requires precise physical dimensions, and power feeding method/location for the antenna.

The objective of this part is to design a single microstrip patch antenna which consists of patch, quarter-wave transformer and feed line. For the patch antenna design, a rectangular patch antenna will be design. Since a $50 \Omega$ surface mount adapter (SMA) connector is going to be used to connect the feed line to the coaxial cable, the feed line will be a $50 \Omega$ feed line. The feed line will be feed to the patch through a matching network which is a quarter-wave transformer. Refer to Figure 3.

A patch antenna has been designed using the patch antenna simulation software CST. We used FR4 for substrate. The center frequency of interest was $\mathrm{fc}=2.45 \mathrm{GHz}$. Some values are required to give in the software input. The following values were assumed as:

1) The operating frequency, $\mathrm{fc}=2.45 \mathrm{GHz}$ 
2) Substrate dielectric constant, $\varepsilon r=4.34$

3) Height of the patch, $h=1.6 \mathrm{~mm}$

The width of the patch [6] is calculated as,

$$
W=\frac{8}{2 f_{2} \sqrt{\frac{5 r+12}{2}}}=37.5(\mathrm{~mm})
$$

And the effective dielectric constant [8] is estimated as,

$$
\varepsilon_{\mathrm{eff}}=\frac{z_{r}+1}{2}+\frac{z_{r}-1}{2}\left(\frac{1}{\sqrt{1+\frac{1 W}{W}}}\right) \approx 4,03
$$

The extended dimensions of the patch along its length $\Delta \mathrm{L}$ is estimated as [8],

$$
\Delta L=0,4,12 \mathrm{~h} \frac{\left(\varepsilon_{\text {eff }}+0,300\right)(W / \mathrm{h} / 0,264)}{\left(\varepsilon_{\text {eff }}-0,258\right)\left(W /{ }_{\mathrm{h}}+0,80\right)}=0,74(\mathrm{~mm})
$$

Now, the length of the patch [8],

$$
\mathrm{L}=\frac{\mathrm{c}}{2 \mathrm{f}_{\mathrm{z}} \sqrt{\mathrm{I}_{\mathrm{sff}}}}-2 \Delta \mathrm{L}=29,02(\mathrm{~mm})
$$

For the width and length of the quarter-wave transformer and $50 \Omega$ feed line in this project are determined by the LineCalc in ADS2009 software. However the value that obtained from Line Calc will be modified to suitable value suite with the fabrication technology that will be use to fabricate the antenna. The obtained values for the parameter are illustrated in the Table 1 below.

Table 1. Widths, lengths of the patch antenna

\begin{tabular}{lccc}
\hline & Patch $(\mathrm{mm})$ & $\lambda / 4$ Transformer $(\mathrm{mm})$ & $50 \Omega$ feedline $(\mathrm{mm})$ \\
\hline Width & 37,5 & 1 & 2,89 \\
Length & 29,02 & 13 & 32,6 \\
\hline
\end{tabular}

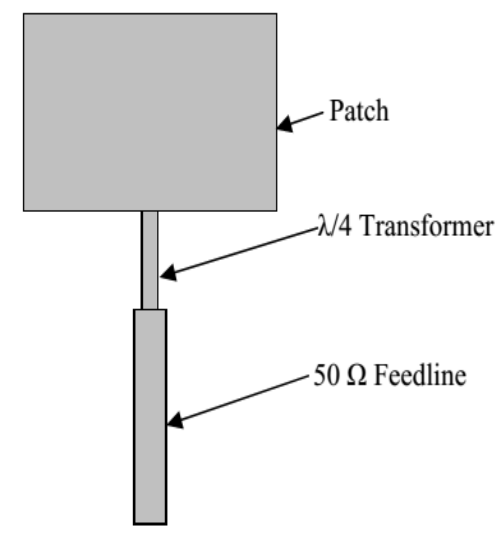

Figure 3. Patch Antenna with Quarter-Wave Transformer

Figure 4 shows the proposed patch antenna, which consists of patch and a microstrip feed line. The circuit was fabricated using micro-strip lines with a FR4 substrate, then observed with the Anritsu 37369D Vector Network Analyzer. The antenna's return loss is figured out in Figure 5. The return loss is smaller -15 $\mathrm{dB}$ at $2.45 \mathrm{GHz}$ meaning that the quite good matching is performed at operating frequency. 


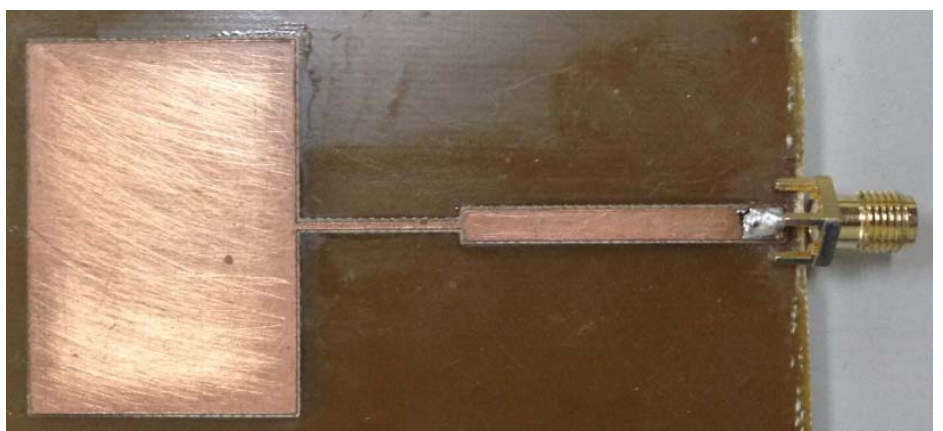

Figure 4. Fabrication of the antenna

\section{RECTIFIR DESIGN}

Rectifier is a nonlinear circuit, which converts RF power into DC power. The main characteristic of the operating effectiveness of rectenna is its efficiency, determined by losses, which arise during its conversion into DC power. The mathematical relation that describes the RF-DC conversion efficiency is given by (4) [6]-[9].

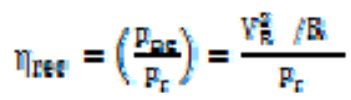

with $\mathrm{V}_{\mathrm{R}}(\mathrm{V})$ the output voltage drop across the load, $\mathrm{R}(\Omega)$ the load value, Pr $(\mathrm{W})$ the RF input power at the receiving antenna's output port, and PDC the DC power entering at the load R.

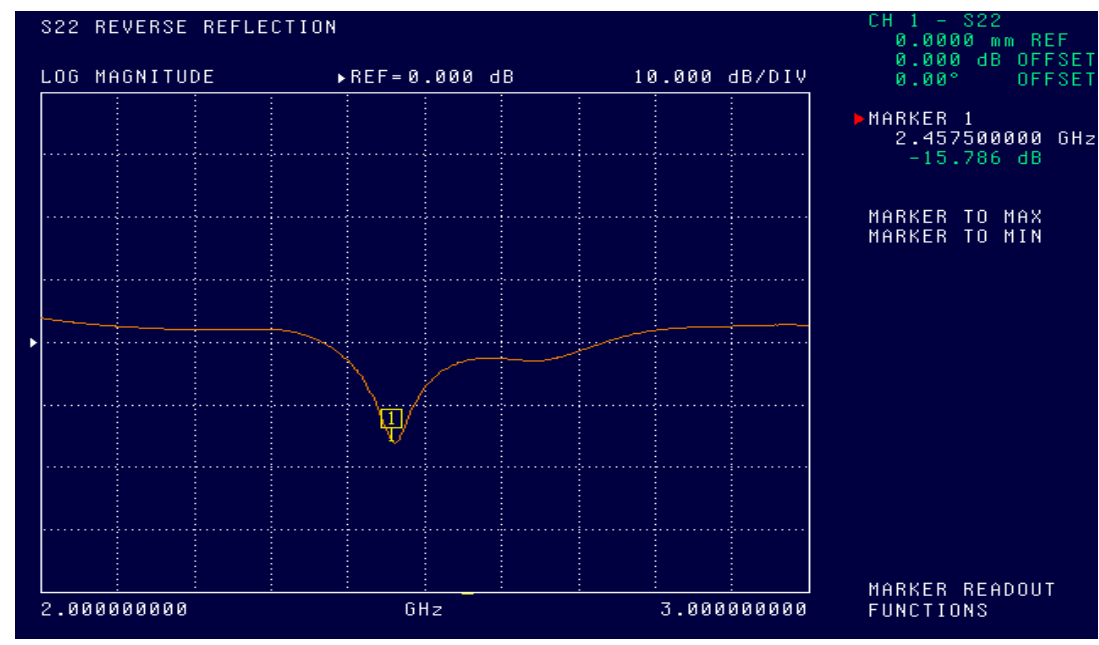

Figure 5. The return loss curves of the patch antenna

The conversion efficiency of the rectifier depends mainly on a power conversion device. Accordingly, the diode must have low reverse recovery time and the conversion efficiency must also be high. A Schottky diode is chosen as conversion device for the design of rectenna system in the study [3]-[5]. In our design a HSMS2820 Schottky diode was used in voltage double rectifier, and has a voltage drop of $340 \mathrm{mV}$. This low voltage drop provides high switching speed and better system efficiency. The choice was made to use HSMS2820 Schottky diode, which has the equivalent circuit parameters as follows, series resistance RS $=6 \Omega$, zero bias junction capacitor $\mathrm{Cj} 0=0.7 \mathrm{pF}$, forward voltage $\mathrm{VF}=0.34 \mathrm{~V}$, and breakdown voltage $\mathrm{VB}=$ $15 \mathrm{~V}$.

The voltage double rectifier (VDR) is an amplitude amplifying circuit that uses dual diodes. Schematic of a double-voltage topology is shown in Figure 6. The voltage double rectifier is composed of a peak rectifier formed by diode D1 and capacitor $\mathrm{C} 1$ and a voltage clamp formed by diode D2 and capacitor 
C2. A dual diodes voltage double with only single capacitor is unpopular but the VDR is a well defined single stage voltage double that doubling the amplitude of input signals [2],[10].

To reduce reflection loss as well as ensure maximum power transfer, a good impedance matching network has to be realized between the antenna and the rectifier's input. First, the diode's equivalent impedances were measured at the expected frequency range $(2.0-2.8 \mathrm{GHz})$ as shown in Figure 7 . The fundamental impedance is of importance since the front end is a tuned circuit and the "harmonic impedances" are filtered out in the application [8].

Given the fact that diode's input impedance is little bit sensitive to the input power, the matching had to be made with a fixed input power [10]. This design was more focused on the $10 \mathrm{dBm}$ to $25 \mathrm{dBm}$ of the input power range.

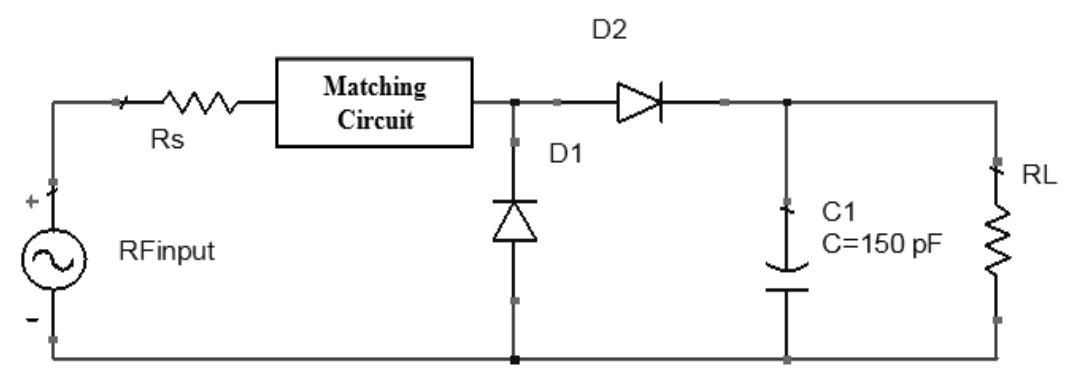

Figure 6. Schematic of a double-voltage topology

A single-stub matching network was designed using Advance Design System (ADS) to achieve a good impedance matching between the elements. The schematic of a VDR is shown in Figure 8. The microstrip lines required for efficient charging and impedance transformation are shorter as compared to the other configurations. As a result, this configuration has the potential to allocate smaller footprint. The merit of smaller form factor is significant because multiple rectifiers are essential in rectenna array. In this circuit, the microstrip line TL2 and TL3 are used for input matching and the microstrip line TL4 is used for output matching. The circuit was designed, simulated and optimized using ADS, then it was fabricated on FR4 substrate for verification.

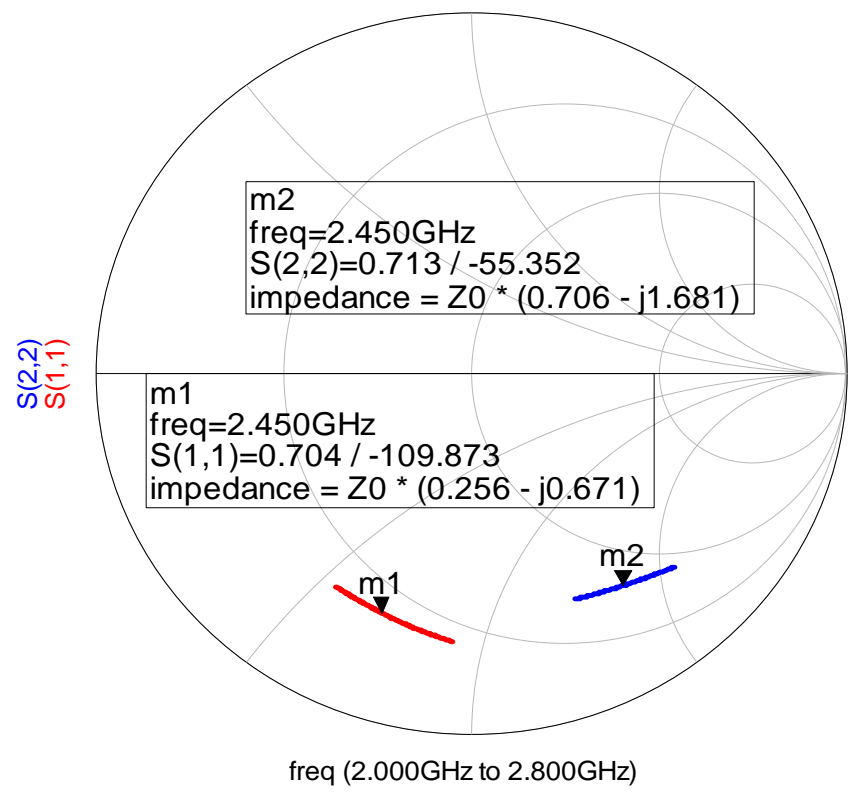

Figure 7. Double Diode's impedances 


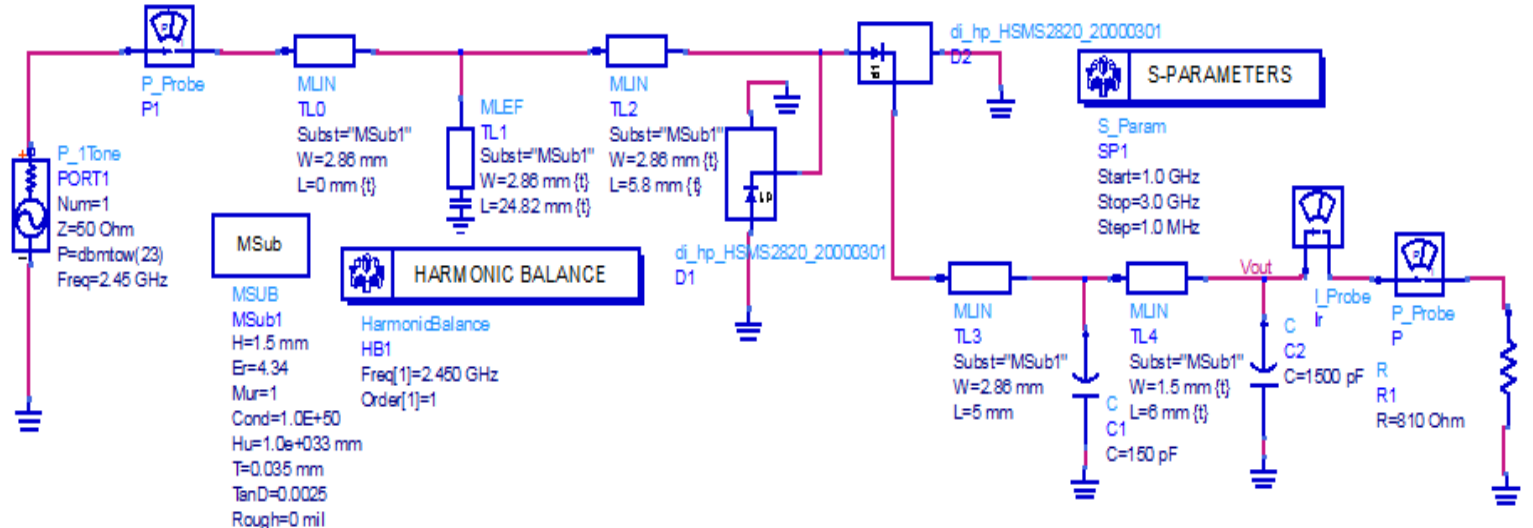

Figure 8 . The schematic of the voltage double rectifier

The layout and fabrication of the voltage double rectifier are shown in Figure 9. The dimension of the rectifier system is $3.5 \mathrm{~cm} \times 2.5 \mathrm{~cm}$. The PCB (Printed Circuit Board) was manufactured by a computercontrolled machine LPFK Protomat - C40.
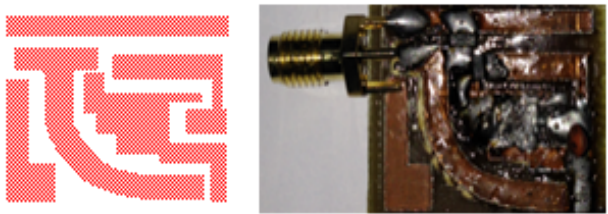

Figure 9. The layout and fabrication of the voltage doubler rectifier

The conversion efficiency is measured with respect to the rectifier load at range of $10 \mathrm{dBm}$ to 25 $\mathrm{dBm}$ of input power. The optimal load resistance is around $810 \Omega$ for $+23 \mathrm{dBm}$ input power at the frequency of $2.45 \mathrm{GHz}$. The measured efficiency values are plotted in Figure 10. Accordingly, the maximum conversion efficiency of $71.5 \%$ is reached at $22 \mathrm{dBm}$ of input power. Compared to the voltage doubler rectifier circuit in [11], this configuration has higher efficiency. From Figure 10, as can be seen that the conversion efficiency increases until the input power reaches $23 \mathrm{dBm}$, then conversion efficiency decreases rapidly. Between $15 \mathrm{dBm}$ and $25 \mathrm{dBm}$ input power, the conversion efficiency exceeds $50 \%$. The DC voltage output level is 7.36 V@20 dBm,10.75V@23dBm and13.24V@25dBm input power respectively.

Compared to the voltage double rectifier circuit in [2] and [11], this configuration has higher efficiency and smaller size.

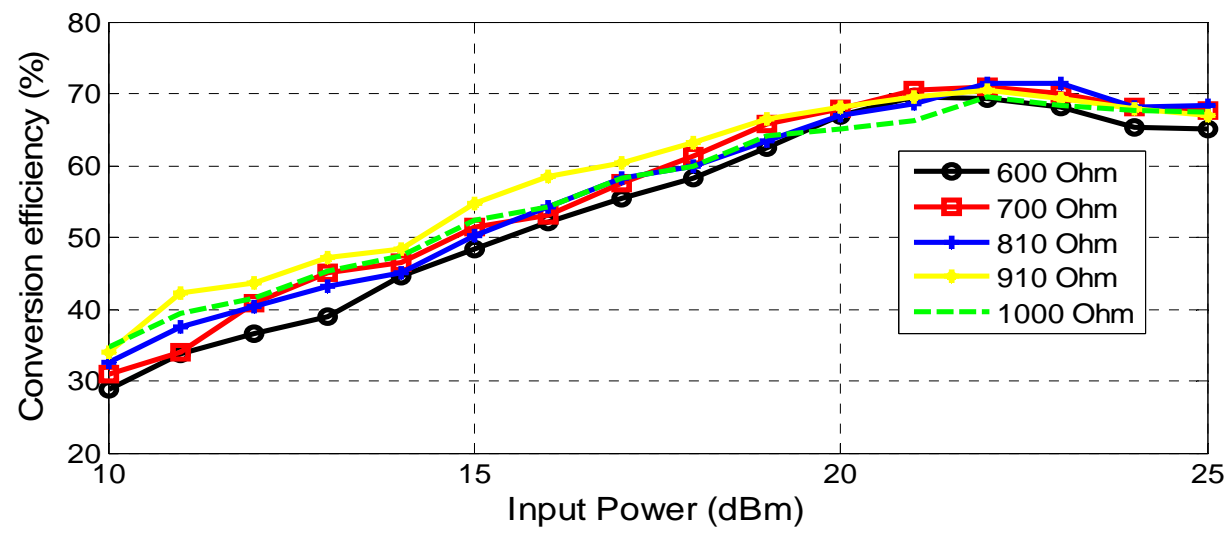

Figure 10. Measured DC voltage and conversion efficiency of the voltage doubler rectifier 


\section{CONCLUSION}

A rectenna is one of the key technologies for microwave power transmission and energy harvesting. The rectenna circuit topology has been studied, designed and fabricated for MPT system. A microstrip patch antenna is designed on FR4 substrate. The return loss is smaller $-15 \mathrm{~dB}$, which means that the impedance matching is quite good. In our voltage double rectifier, the HSMS2820 Schottky diode was selected to design, simulation and fabrication the voltage double rectifier circuit used for microwave power transmission system. Good performances have been obtained in terms of RF-DC conversion efficiency. In this work, we have proposed a $71.5 \%$ conversion efficiency rectifier at input power level $22 \mathrm{dBm}$. In view of these results, in future work, the objective is to increase the rectenna performance.

\section{ACKNOWLEDGEMENTS} QG.15.27.

This work has been sponsored by Vietnam National University, Hanoi (VNU), under Project No.

\section{REFERENCES}

[1] N. Shinohara, "Rectennas for microwave power transmission," IEICE Electronics Express, vol/issue: 10(21), 2013.

[2] W. S. Yeoh, "Wireless power transmission (WPT) application at 2.4 GHz in common network," RMIT University, Doctor of Philosophy's Thesis, March 2010.

[3] D. Zhao, et al., "Multiple-Input Single-Output Wireless Power Transmission System for Coal Mine," TELKOMNIKA Indonesian Journal of Electrical Engineering, vol/issue: 12(6), pp. 4572-4578, 2014.

[4] D. Zhao, et al., "Design and Simulation of Multiple Coil Model for Wireless Power Transmission System," TELKOMNIKA Indonesian Journal of Electrical Engineering, vol/issue: 12(6), pp. 4166-4177, 2014.

[5] Z. Harouni, et al., "Efficient $2.45 \mathrm{GHz}$ Rectenna Design with High Harmonic Rejection for Wireless Power Transmission," IJCSI International Journal of Computer Science Issues, vol/issue: 7(5), 2010.

[6] C. Liu, et al., "Study on an S - band rectenna array for wireless microwave power transmission," Progress In Electromagnetics Research, vol. 135, pp. 747-758, 2013.

[7] S. Riviere, et al., "A compact rectenna devide at low power," Progress In Electromagnetics Research C, vol. 16, pp. 137-146, 2010.

[8] M. Biswas, et al., "Design a Prototype of Wireless Power Transmission System Using RF/Microwave and Performance Analysis of Implementation," IACSIT International Journal of Engineering and Technology, vol/issue: 4(1), 2012.

[9] Y. Y. Gao, et al., "A circularly polarized rectenna with low profile for wireless power transmission," Progress In Electromagnetics Research Letters, vol. 13, pp. 41-49, 2010.

[10] P. M. Masud, "A methodology for designing $2.45 \mathrm{GHz}$ wireless rectenna system utilizing Dickson Charge Pump with Optimized Power Efficiency," Thesis Master of Applied Science in Electrical and Computer Engineering, 2013.

[11] D. H. Chuc and B. G. Duong, "Investigation of Rectifier Circuit Configurations for Microwave Power Transmission System Operating at S Band," International Journal of Electrical and Computer Engineering (IJECE), vol/issue: 5(5), pp. 967 974, 2015.

\section{BIOGRAPHIES OF AUTHORS}

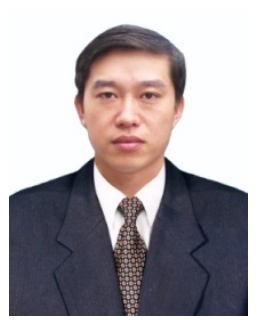

Doan Huu Chuc was born in Hai Phong City, Vietnam, in 1978. He received the B.S. and M.S. degrees in engineering electronics from the Vietnam National University (VNU), Hanoi in 2000 and 2007, respectively. He is a Lecturer of Department of Electrical and Electronics, Hai Phong Private University. He is currently pursuing the Ph.D. degree in electronic engineering at VNU, where his dissertation is focused on microwave circuit designs for wireless power transmission and high power semiconductor amplifiers. Email: chucdh@hpu.edu.vn

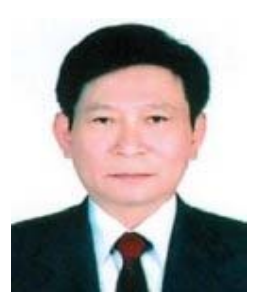

Assoc. Prof. Bach Gia Duong was born in Ha Dong Dist, Hanoi, Viet Nam, in 1950. He received the B.S degree in radio physics in 1972 and the Ph.D. degree in wireless physics from University of Science, in 1988. Since 2006, he is a Lecturer and Head of Electronics and Telecommunication Center, University of Engineering and Technology, Vietnam National University. He is the author of three books and more than 80 articles. His research focuses on RF Analog Signal Processing, RF chip design, Radar Engineering and Technology, Automatic Control. Email: duongbg@vnu.edu.vn 